\title{
A 12 YEAR ANALYSIS OF DISSOCIATIVE STUPOR AND POSSESSION IN A PRIVATE PSYCHIATRY OPD
}

Dua Neuro Psychiatric Centre, Lakhimpur Kheri, UP, INDIA

Dissociative Disorders are not as rare as are thought to be. Sar et al (2000), reported $12 \%$ incidence of Dissociative Disorder in a psychiatric outpatient clinic in Turkey. Sar et al (2007) also reported an incidence as high as 34.9\% in emergency psychiatry OPD. Foote et al (2006) turned out with a $29 \%$ incidence in an inner city hospital based psychiatry OPD. Chaturvedi et al (2009) reported an incidence between 1.5 and 15 per 1000 in an institute in India including both inpatients and out patients. Nandi et al (1992) suggested that hysteria is on the wane in a study in west Bengal villages. However, most of the studies suggest an incidence of 85-100 per 1000 of psychiatry OPD population. All the above studies also suggested a $4: 1$ ratio in favour of females across all ages.

OBJECTIVE: To study the incidence of Dissociative Stupor and Posession in a psychiatry OPD population. To analyse the gender distribution and the predominant age of presentation.To study gender diferences in the preadolescent ages. This is a longitudinal research of 15 years of which the data of last twelve consecutive years is presented and analysed here.

METHOD: All new patients attending a private psychiatry OPD in a small township of India at Lakhimpur Kheri in Uttar Pradesh, were screened to identify cases of Dissociative Disorder according to ICD 10, F44.2 and F44.3 from the 1st of January to 31st of December each year from 2005 to 2016. From these screened cases, only those presenting with episodes of unconsciousness and possession, were analyzed and compared with the other years for the same period.

RESULTS: Out of the total 57,953 new patients seen in the twelve years $(32,016$ males and 25,937 females) 5,283 patients,(9.11\%), fell into the screened group (1105 males and 4178 females $-1.9 \%$ and $7.21 \%$ respectively).

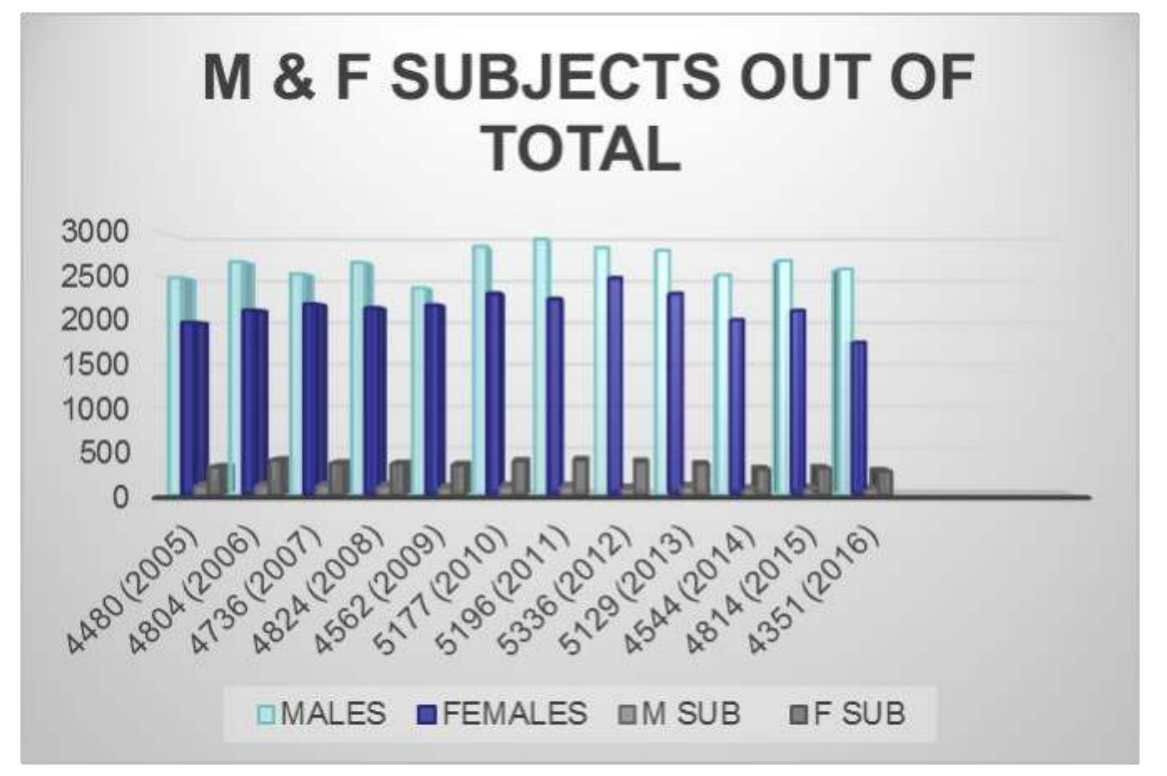

When compared within, there were around $10 \%$ of the subjects in $2005-06$ sliding through to $7.76 \%$ in 2016 , a visible decline. The mean age of patients in males and females was also quite similar through the years. The mean age of the subject group was 18.87 years for males and 23.06 years for females. The range of mean age for males was between 17.4 and 20.2 years while for females, it was between 22.1 and 24.13 years during the study period of twelve years.

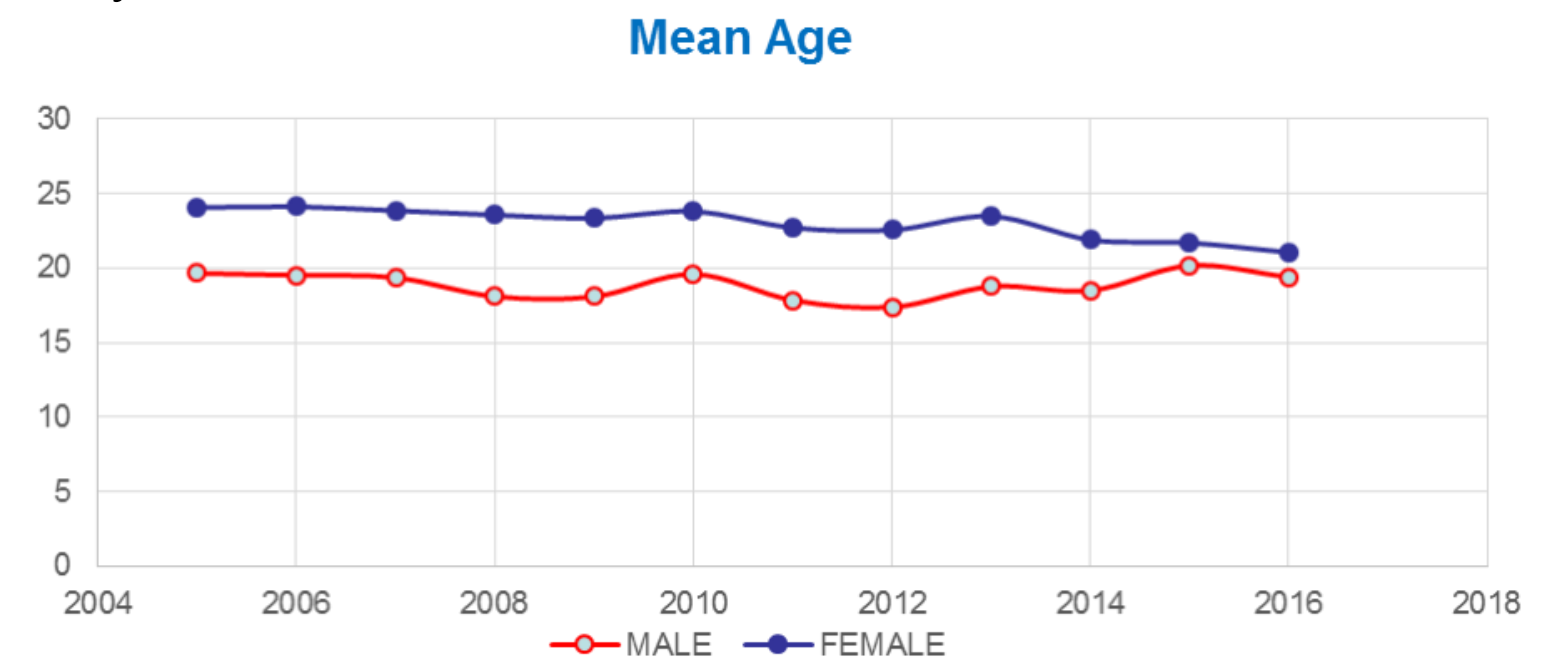

CONCLUSION: The above study, therefore, supports the observation that there is a visible decline in incidence of dissociative stupor and possession from $10 \%$ to $7.76 \%$ in twelve consecutive years. This decline does not dilute the fact that this illness cannot be ignored, considering the number of manhours going into its management. This study also showed that males are affected earlier (mean age 19.26 years) than females (mean age 23.87 years), may be attributed to career planning in boys which begins at this age. Likewise, for females, it may be attributed to cultural factors such as early marital alliances, around 22 years, which may be potential source of stress. The study again proved that females far outnumber males in this category of illness but in the ages between 6 to 12 years, this relationship is reversed. The boys outnumber girls in this category in almost all the twelve years with a ratio of $1.3: 1$ as compared to the $13+$ group. In 2015 , the ratio is almost 2:1.
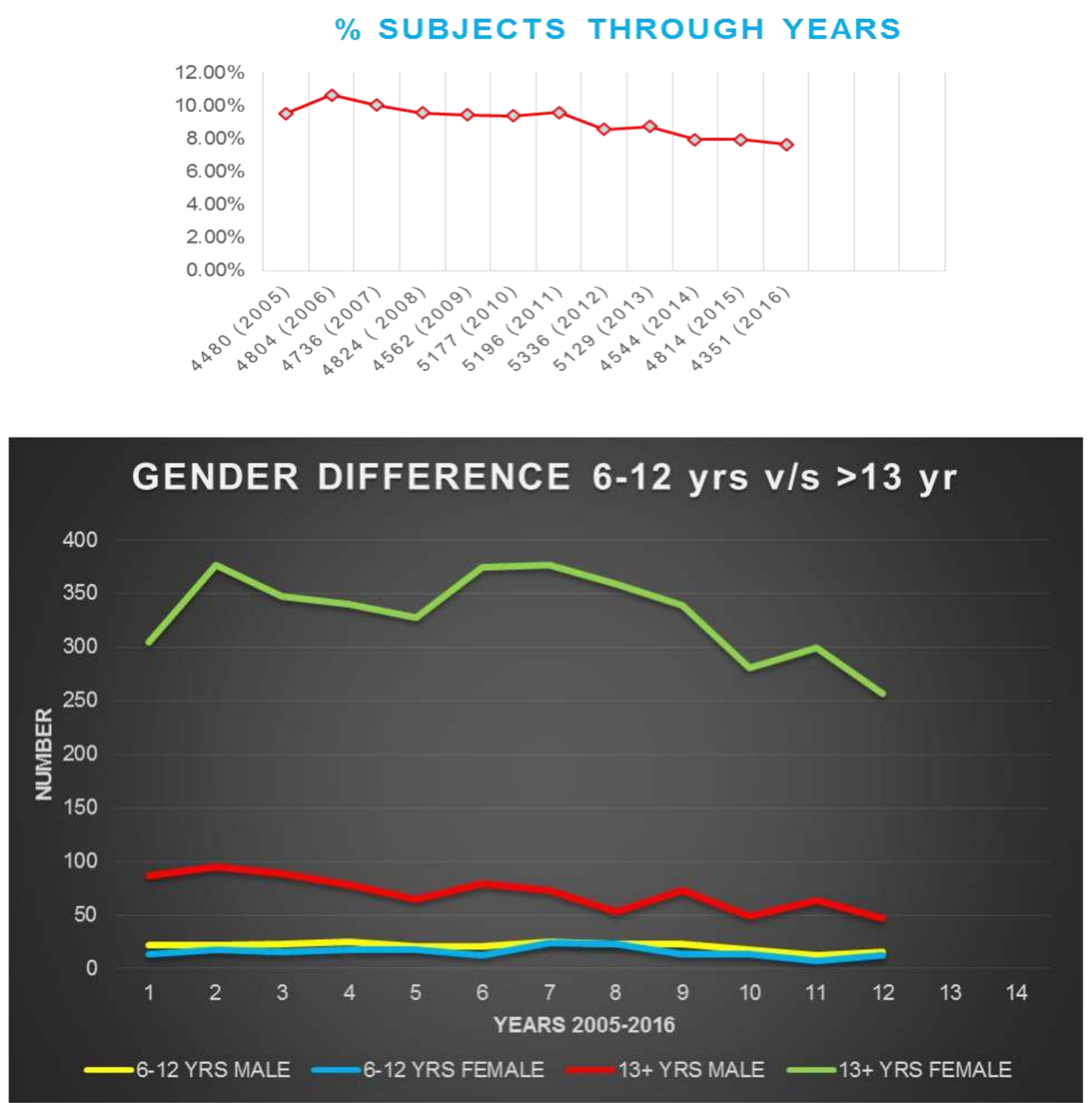

GENDER DIFFERENCE 6-12 YRS

口6-12 YRS MALE $\approx 6-12$ YRS FEMALE

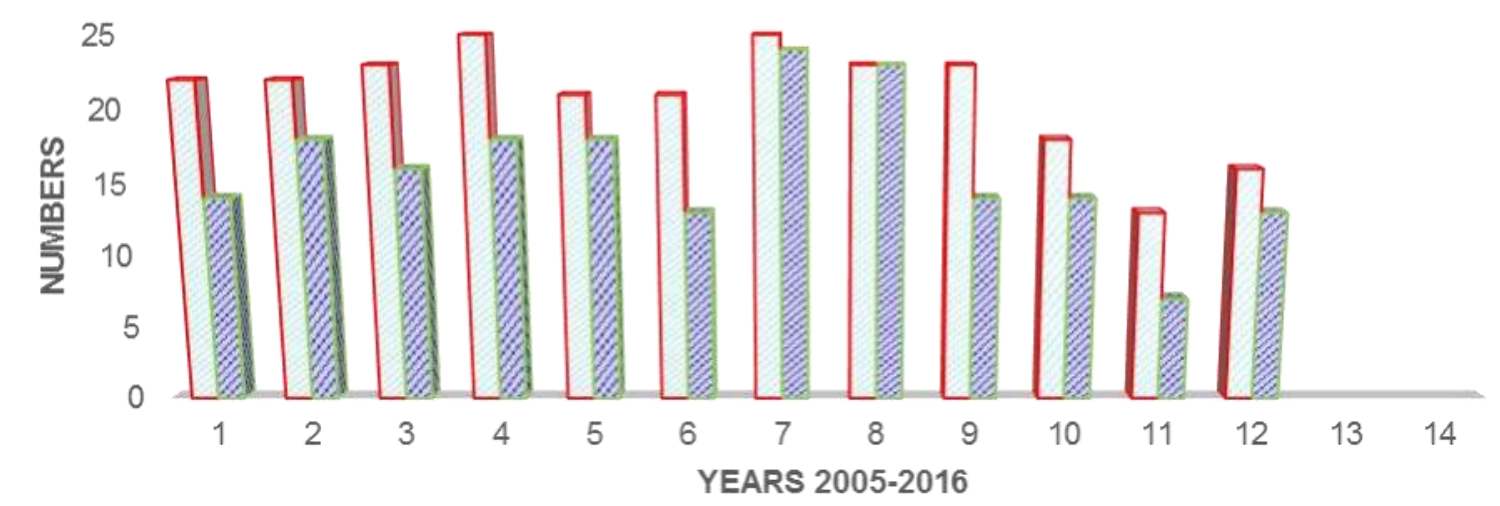

This inverse relationship may be attributed to the factors such as males being the favoured gender in the society in comparison to girls; and expectations for males to take financial responsibilities for the family as early as possible in some communities. Statistical analysis has proved the significance in the twelve years and it is to be seen if repeated when all 15 years are analyzed.

\section{SOURCES;}

Psychiatry by Tasman, Kay and Lieberman. Second Ed. Textbook of Psychiatry by Hales, Yudofsky and Gabbard. Fifth Ed World Wide Web (Google). 